\title{
Discussion and Analysis of Role of Vocalization in Vocality Teaching
}

\author{
Zhihua Liu
}

Art Institute, Shangluo University, Shangluo Shaanxi, 726000, China

Keywords: Vocalization, Vocality teaching, Role.

\begin{abstract}
Vocalization is an important part of vocality teaching. Effective learning of vocalization can help students to quickly grasp vocalizational and singing skills, and improve their vocal music level. However, many students don't understand the significance of vocalization to vocality teaching well. Thus, this thesis is written to make analysis from the angle of main meaning and development of vocalization to figure out main methods of vocality teaching, and discuss the positive role of vocalization in vocality teaching.
\end{abstract}

\section{Introduction}

Vocalization is a method specially designed for vocality teaching, and has been widely popularized and applied in the teaching field in China. Vocalization plays an important role in professional vocal music talent cultivation in China, and in Chinese vocal music education. Presently, there is a large development space for vocality teaching. Yet vocality teaching has not been fully popularized, and has lots of problems in actual development. Thus, the study on vocalization becomes a main part of discussion and analysis of vocality teaching.

\section{Vocalization Overview}

In recent years, with the constant popularization of art forms, vocal music art has attracted broad attention and interest. At first, vocal music was thought to be an elegant art, and helpful to cultivate people's taste. Most people, however, don't truly understand vocal music art but appreciate it only. Some ones also study performing vocal music. As to vocal music learners, exercising vocalization will make a great difference to their singing and behavior standard. Thus, vocalization is regarded as the most basic singing exercise method. To form a good singing habit, learners ought to correctly understand the concept of vocality, so as to facilitate their learning subsequently and realize their development value in the singing field. Vocalization originated from traditional vocality teaching system in the western, and became an important part of singing teaching. Vocalization is performed with a single vocal or multiple vocals or realized by means of no-word vocal exercise or music concert $^{[1]}$. It is said that a famous Italian singer learned vocal music from a master in the eighteenth century, the master composed over 60 vocalizations for her for exercise during the learning period, and she made a hit in subsequent singing performance despite that she never did systematical vocalization exercise. This story seems to be a little exaggerated, but implies that vocalization exercise can facilitate singing. So far, there is no normative systematic vocalization education system formed in China yet, though few related teaching materials had been compiled, such as the 30 Vocalizations for Articulation in Singing by Song Chengxian, etc. Vocalization relatively differs from vocalization practice. Generally, vocalization practice is relatively simple, and is mainly performed with arpeggio or scale, and sound transition is smooth and steady. It is not the case for vocalization, which refers to special specific exercise based on songs. For example, some vocalizations were made to train voice production and breath, some to train flexibility and jumpy of voice, and some to train staccato, legato, and tone leap. Vocalization itself is beautiful, and of good effect of exercise. Thus, in teaching, vocalization is not just a exercise, but also a beautiful melody.

\section{Current Situation of Vocalization Teaching}

Learners are likely to encounter some problems in vocalization study, because vocal music learning has unique characteristics, and the vocal organs and resonance apparatus vary from person to 
person.

Vocalization exercise is a key part in vocal training and teaching, and a base part in vocal music learning. The basic exercise of vocalization mainly aims to lay a solid foundation for singing. Thus, vocalization is an important link in vocal music teaching. However, a correct understanding about the utilization of vocalization teaching materials hasn't been developed yet, and the use procedure is also not normative. Thus, to make full use of vocalization teaching materials, the contents should be full understood first. It must be avoided to select teaching material at will. For example, for bass, the Exercise for Improving Voice should be selected. Besides, learners are supposed to, based on their own conditions, adjust their transposition and vocals. For a beginner of soprano, the Vocailses of J. Concone is appropriate. For those who enunciate unclearly, the vocalization materials of Wang Pinsu and Song Chengxian are appropriate. Besides, in most cases, only vocalization skill training is emphasized in vocal music teaching, and musical expression forms are ignored. One music work will impress audiences differently due to different singers. This is mainly because that singers' musical accomplishments are different.

Thus, vocalization exercise should be performed on certain basis. In vocal music teaching, what effect will be achieved via exercise and whether the selected vocalization materials are suitable are very important. For example, those who are less able to master voice flexibility will not practice songs for training breath, but songs for training staccato or speed. If learners appear poor in breathing, then teachers will take measures to avoid this by, say, letting learners sing some short verses or songs less demanding for breath as far as possible. In that case, learners will never get improved in breath, nor touch related works, so that these learners cannot get somewhere in singing. Therefore, individualized quality education should be achieved based on learners' conditions in vocalization teaching, selecting proper vocalization materials for learners, analyzing the common problems occurring during exercise, and comprehensively improving learners' singing skills, to design valuable singing exercise for learners.

\section{Role of Vocalization in Vocal Music Teaching}

\section{Helpful to train singing skills.}

Vocalization is helpful to train learners' singing skills and capability. This is because that vocalization and voice training in other forms are more helpful to express song form, and even the difficulty and technique difficulty of songs are closely related to songs. Thus, learners ought to be instructed to practice different skills based on their own needs, to break through various singing skills, develop their singing skills, and improve their singing capability. Take the example of the Spicker Advanced Vocailses Collect which covers a series skills, such as liaison, syncopation, staccato, tercet and trill, etc. Thus, learners can train these skills through practicing this material.

\section{Helpful to reinforce emotion in singing.}

Vocalization is helpful to reinforce learners' emotion factors. Through years of practice and development, a complete structure and knowledge contents of vocalization teaching have been formed. Thus, vocalization is a form of song to a certain extent. Learners can practice their emotions through practicing vocalizations, because vocalizations were integrated into emotions of composers. Besides, learners ought to pay attention to intensity, speed, ligature, and conditions for staccato occurring, take notice of potential changes of voice, and try their best to express the emotion factors contained in works. Simple vocalization practice is not advisable, but training learners to completely express their voices is. On in this way, a solid foundation for future development can be laid ${ }^{[2]}$.

\section{Helpful to solve problems relating to articulation.}

Vocalization is helpful to solve problems relating to articulation. Articulation, also referred to as pronunciation in singing, is an important singing skill. Articulation will directly singing learners in respect of singing level and singing capability. Singers should pronounce accurately and articulate, and perform skillfully with beautiful songs and with rich feelings. Concerning articulation, singers should make certain about the separation of sharp and round tone, five notes and recognition of sonorant and nonsonorant, and clearly accurately express themselves in words. The 4 Vocalizations for Articulation in Singing by Song Chengxian can be used for guiding articulation, which collected 
several years of teaching experience of Song Chengxian, was compiled based on accurate judgment about Chinese language according to the thirteen rhymes, and is in particular suitable for main vowel and rhyming practice. The 69 Vocalizations Combining Words and Sound by Shi Weizheng is helpful for Chinese learners to practice articulation emphasized in vocal music teaching in the western, because it compares vowels of Chinese language with that of western languages.

\section{Helpful to arouse learners' enthusiasm.}

Vocalization is helpful to arouse learners' enthusiasm and initiative. Through years of development and research, a sound vocalization system has been realized, so that itself becomes attractive, and is more effective to arouse learners' enthusiasm and initiative than ordinary vocality teaching is ${ }^{[3]}$. If learners practice vocalization on their own initiative, they can not only improve their learning efficiency, but also become positive and optimistic to fulfill tasks. In this way, vocalization is not just taken as a task or even pressure. On the contrary, learners will learn to constantly think and research on their own initiative, and practice based on their researches and knowledge base, which in turn will facilitate practice.

\section{Helpful to regulate learners' vocal music learning.}

Vocalization is helpful to promote systematical and normative vocal music learning. For example, both the Vocailses of J. Concone and the the Spicker Advanced Vocailses Collect were developed through constant investigations and systematic researches and based on the composers' own vocalization practice experience and summarization about difficulties and singing skills. These vocalizations are of high artistic value, formed a systematic and normative vocality teaching guide form, and help vocality learners' to develop their own values.

\section{Vocalization Teaching Method in Vocality Teaching}

\section{Select proper songs.}

To train vocalization, proper songs should be selected first, and ration teaching measures should be taken. Vocal music learners practice vocalization mainly aim to improve their singing level ${ }^{[4]}$. Thus, learners ought to select proper songs for vocalization practice based on their actual conditions such as advantages and disadvantages. In this mode, selection of songs must not be made at will. Only nichetargeting teaching can achieve good effect. Besides, people differ from each other in respect of advantage and disadvantage. Thus, learners must know well about themselves, overcome their own disadvantages, make rational use of their advantages. Only in this way, they can correctly practice vocalization, and reach a good effect.

\section{Train breath.}

To achieve a good music teaching effect, breath training is of great significance. A good control of breath is required for singing well. Thus, besides movements and vocalization practice, learners also should practice breathing. At the beginning, learners can select simple verses or related songs for vocalization practice, and increase the practice difficulty, to gradually get a good control of breath ${ }^{[5]}$. In breath training process, it needs to be noted that breath practice should be optimized mainly via the muscles of the throat and vocal cords, quick success and instant benefits are definitely unadvisable, which will worsen the singing level and skills.

\section{Add in emotion factors.}

Learners should add in their emotion factors while vocalization practice. Vocalization is not just pronunciation. Narrowly, vocalization refers to music score without lyrics. Every singer will have his own understanding about each verse. Singers will comprehend such vocalization differently, so as to express their different emotions. Some learners also are unable to grasp musical emotions and the artistic conception. Thus, promoting emotional practical at the time of vocalization practice can greatly improve singers’ capability.

\section{Conclusion}

Through analyses and discussions on vocalization above, it can be seen that vocalization is helpful to improve learners' music accomplishments and skills, raise their team awareness and 
cooperative ability both in life and learning, and promote learners' communication and exchange. There are certain laws on vocalization teaching, and a normative training process from simple to difficult and from shallow to deep has been formed, indicating the development direction of vocality teaching in China.

\section{References}

[1] Shao Yun. On the Role of Vocalization in Vocality Teaching, Yellow River of the Song,2013(13):28-29.

[2] Peng Danxiong. Importance of "Music Concert Vocalization" to Vocality Teaching, Jiaoxiang--Journal of Xi' an Conservatory of Music,2014(4):126-128.

[3] Liu Hua. Brief Discussion on the Role of Vocalization in Vocality Teaching, Dazhong Wenyi, 2014(11):244.

[4] Yang Changling. Research and Analysis of the Role of Vocalization in Vocality Teaching, Northern Music, 2014(8):81-82.

[5] Zhao Rui. On the Role of Vocalization in Vocality Teaching, Literature Life, 2015(3):234-234. 